\title{
Desbordes de la pulsión: sexo indiscriminado en adolescentes
}

\section{Overflow of the drive: indiscriminate sex in adolescents}

\author{
Zambrano G., Rosa María \\ Extensión San Pablo de La Troncal \\ Universidad Católica de Cuenca \\ rmzambranog@ucacue.edu.ec
}

\begin{abstract}
Resumen
El objetivo de este reporte científico es identificar las causas que provocan que los adolescentes desborden su pulsión manteniendo sexo indiscriminado. Se hace un recorrido por la adolescencia desde el psicoanálisis, desarrollando los conceptos de subjetividad, identificación, función paterna, castración, acto y acting-out, pulsión, los tipos de pulsión, y destinos de la misma; el cuerpo, el deseo y el goce; se analizan tres casos clínicos que sostienen las argumentaciones teóricas que confirman que el trabajo clínico con adolescentes, dada la condición que caracteriza a sus protagonistas, circula permanentemente por una serie de pulsiones que se desbordan.
\end{abstract}

Palabras clave: Adolescentes, desbordes de la pulsión, sexo indiscriminado.

\begin{abstract}
The scientific objective of this report is to identify the causes that teenagers overflow maintaining indiscriminate sex. A journey through adolescence is made from psychoanalysis, developing the concepts of subjectivity, identification, paternal function, castration, act and acting-out, pulsion, pulsion types; body, desire and enjoyment; three cases that support the theoretical arguments that confirm the clinical work with adolescents, given the condition that characterizes the protagonists, constantly circulates through a series of pulsions that are overflowing.
\end{abstract}

Key words: Teenagers, pulsions, indiscriminate sex.

\section{Introducción}

La adolescencia es un singular período de la vida de cada sujeto, de complejas transformaciones; de una oscilación de investiduras narcisistas y objetales; marcada por el protagonismo de la sexualidad. "Este conjunto de transformaciones violentas producen, en un buen número de adolescentes en la sociedad occidental, vivencias de angustia, inseguridad y depresión asociadas a las pérdidas que supone dejar de ser niño" (Aberastury, 1978, pág. 60).

Dichas pérdidas están referidas al cuerpo infantil, a los padres de la infancia y a las gratificaciones obtenidas de ellos por ser un niño; también se vinculan al yo infantil, al abandonar los hábitos, intereses, roles y conductas infantiles; finalmente el adolescente siente como pérdida el no ser percibido como un niño por parte del entorno familiar y social. (Fernández Mouján, 2002).

En Freud, la adolescencia es situada en la perspectiva del desarrollo de la sexualidad infantil, como un segundo comienzo, después de la interrupción que implica la denominada etapa de latencia. Es de importancia considerar las polémicas actuales en el campo del psicoanálisis en su lectura del texto freudiano sobre el problema de la adolescencia como mera reedición de los avatares de la sexualidad infantil, por un lado; y por otro, la adolescencia como el surgimiento de un momento discontinuo que implica la aparición de nuevos problemas, una ruptura tanto a nivel de las identificaciones como de las relaciones del sujeto con el sexo.

En la enseñanza de Lacan, y en el marco de las relaciones de la estructura con el desarrollo, la adolescencia es abordada en diferentes momentos de su recorrido, en los que se privilegian problemáticas específicas concernientes a los tiempos de constitución del sujeto y las relaciones e intersecciones de los registros simbólico e imaginario. Será a partir de la reformulación del Edipo Freudiano en su articulación con la castración que Lacan aborda las transformaciones necesarias que permiten al sujeto inscribirse en la estructura y asumir una posición en la relación con el otro sexo.

Sin embargo, es de destacar el carácter discontinuo y problemático que ha abordado la adolescencia como momento de transición en el que nada está preparado por los pasos previos, sino por el contrario, se trata para el sujeto de realizar elecciones en las cuales se ponen a prueba identificaciones pretéritas y las respuestas obtenidas concernientes al saber sobre el sexo. Es de importancia considerar los cambios que en el curso de la enseñanza de Lacan se producen en su consideración de la estructura del Otro, así 
como de la función y estatuto del Nombre del Padre, en sus repercusiones sobre el tratamiento del momento de la adolescencia en la que el sujeto debe enfrentar la prueba del ejercicio de su sexualidad.

Leslie Arvelo (2003) respecto a la adolescencia señala que el adolescente se ve dominado por intensas pulsiones sexuales y agresivas, las cuales van a determinar, con cierta frecuencia, actos donde lo inconsciente rebasa las defensas yoicas (exo-actuaciones) que muchas veces ponen en peligro al joven o a su grupo de pares, tales como fuertes explosiones de violencia hacia los demás o hacia sí mismo, transgresiones a normas sociales (consumo de drogas, pandillas, robos), conductas sexuales de riesgo (contagio de sida, enfermedades venéreas, etc.) embarazos precoces, intentos suicidas deportes riesgosos, actitudes y conductas provocadoras masoquistas) entre otras. Frente a estas fuertes pulsiones el adolescente responde también con poderosas defensas como la disociación (entre objetos, entre afecto e intelecto, cuerpo y pensamiento) proyección, represión, inhibición, aislamiento, formaciones reactivas, idealización, intelectualización.

El psicoanálisis se ha ocupado de la adolescencia. Muchos aportes han sido desplegados desde que su descubridor Sigmund Freud le dedicara un importante tiempo y análisis a la pubertad en su obra; así como las enseñanzas de Lacan a través de la relectura que hiciera de la obra de Freud. Sin embargo, en el psicoanálisis no todo está dicho, muchas preguntas surgen cuando se hacen coincidir significantes tales como adolescentes, desbordes de la pulsión, sexo indiscriminado. Ello abre el espacio para una nueva interrogante, una falta en saber que permite una nueva articulación en el entramado clínica-teoría.

Pensar en la práctica de sexo indiscriminado en los adolescentes lleva a planteamientos como son: ¿qué es un adolescente para el psicoanálisis?, la adolescencia es una etapa crítica que siempre supone riesgos y peligros sea que se la plantee como un momento de cambios y duelos, como una crisis a acompañar, como una encrucijada con posibilidades creativas, como un momento de transición. Todo adolescente vive necesariamente una crisis que por lo general implica una riña con el mundo adulto. Los adolescentes se enfrentan al despertar de la sexualidad y presentan sentimientos inciertos que varían entre el miedo a las transformaciones y el júbilo por desarrollarse y crecer.

La metodología de investigación utilizada fue la cualitativa con enfoque interpretativo para profundizar en el estudio o análisis del fenómeno del desborde de la pulsión en los adolescentes mediante el estudio de casos. Se empleó la entrevista a profundidad. La categoría de análisis fue la pulsión y los identificadores considerados fueron los desbordes de la pulsión: causas y manifestaciones.

Se analizaron los desbordes de la pulsión de tres adolescentes internados en una clínica de reposo psiquiátrico en la ciudad de Guayaquil. En el Caso 1 la adolescente asume su cuerpo como un "real", confirmando que la adolescencia está caracterizada por la irrupción de lo pulsional y los cambios. La adolescente se impone una imagen facial "perfecta" que promueve la práctica de relaciones sexuales de manera compulsiva y adictiva. Después de la supuesta conformidad que brinda una relación sexual indiscriminada, la adolescente experimenta una situación angustiante, que carga la falsa promesa de satisfacción, que ocurre justo al cuestionarse acerca de su malestar. Hay una destitución del saber de los padres, al aparecer la rebeldía con sus padres como reacción frente al vacío promovido por los cambios en su cuerpo; una búsqueda de un nuevo soporte como modo de evitar el contacto con aquello que da cuenta del vacío.

En el Caso 2 la adolescente vive una situación de urgencia, de hallar una nueva manera de ser y busca escapatoria para su malestar en objetos sustitutos: conductas sexuales indiscriminadas y de riesgo. Ha tratado de mitigar su desasosiego a través del acto, que tiene un sentido específico vinculado con la problemática inconsciente del sujeto. La fragilidad de la adolescente se rebela en forma de desencadenamiento psicótico. En la adolescencia, cuando se derrumba la fachada de las identificaciones imaginarias de la infancia, el sujeto puede estar ausente; angustia, despersonalización, agujero negro, apelación al tóxico... y sobreviene el hundimiento psicótico.

En el Caso 3 se confirma que la adolescencia es la ubicación de un tiempo en donde el sujeto debe inventar nuevos semblantes frente a ese desarreglo que aparece en el cuerpo y surgen las preguntas sobre el sexo, sus identificaciones, sus creencias. Se vive una época donde la felicidad se mide en términos de satisfacción inmediata, sin medida, sin incidencias ni retornos que promueve un derecho al goce. La adolescente frente al peligro que significa su relación con la pulsión mortífera, la castración no viene a limitar el empuje a la satisfacción. De ahí que mantiene relaciones sexuales promiscuas para evitar un peligro mayor que es su muerte subjetiva. La adolescente puso su vida en riesgo para separarse del Otro, trata de separarse de la mirada superyoica de su padre para de alguna manera crear ese margen que necesita para vivir. Así mismo emplea a los pares EMOS como un medio para adherirse a lo mismo, estableciéndose como un modo de separación necesaria con el Otro. La adolescente trasladó toda su ira a su cuerpo al practicarse autolesiones. Realizó un pasaje al acto cuando intentó quitarse la vida.

\section{Discusión}

De acuerdo al objetivo general planteado en esta investigación se han determinado las causas que provocan que los adolescentes desborden su pulsión manteniendo sexo indiscriminado: a) La adolescencia es un despertar a la sexualidad, en el que el sujeto se encuentra con lo real y trata de hallar una salida con respuestas particulares y es entonces cuando aparece el síntoma que trae consigo sufrimiento y perturba su tranquilidad. El adolescente ante esta problemática es un sujeto que demora en tomar decisiones. La participación de los padres en la formación de sus 
hijos transmitiéndoles ideales difíciles de alcanzar, hacen que estos se rebelen y para poder sostener su deseo, hacen actuaciones que llamamos acting out y que se sintomatizan como por ejemplo relaciones sexuales indiscriminadas, sin protección, con riesgo de embarazos en la mujer y riesgo de que se les transmita el virus de inmunodeficiencia humana (VIH), enfermedades venéreas, el virus del papiloma humano, etc. b) La crisis de las familias estrechamente relacionadas con la decadencia de la función del padre como soporte de la castración y de protección que deja al sujeto a órdenes cada vez más opresivas de la civilización moderna y el cuestionamiento de la organización familiar tradicional en la sociedad actual, jóvenes que pasan mucho tiempo solos sin oportunidad de intercambio simbólico con sus padres.

Desde el psicoanálisis se profundizó que la pulsión es una energía constante a lo largo de toda la vida del sujeto; la libido no cambia, ni cambiará en donde se coloca, puede ser controlada, puede ser desplazada, pero no puede ser reprimida, pues de lo contrario puede ser más actuada, pero en sí la pulsión es constante. Así es también a modo de ejemplo, con la misma energía que un bebé de meses de nacido se prende del seno de su madre que con la que el adolescente de 15 años se prende de un concierto de música del artista de moda o mantiene sexo indiscriminado. Se trata por lo tanto que en la adolescencia hay una redistribución del deseo y de las identificaciones.

Se estableció que hay un momento para el sujeto en que ya no anhela lo que anhelaba antes; ya no goza de las mismas cosas; todos los modos de satisfacción infantiles se ven marcados por una barrera que el adolescente lo considera como cosa de niños. Como el deseo del sujeto está marcado con la pérdida de los goces infantiles, para el adolescente le es difícil abandonar estos modos de satisfacción infantil, sobre todo porque aparecen estrechamente relacionados o marcados por el Otro, sean quien sea quien encarne ese Otro, madre, padre, familia; el sujeto dirá yo no soy responsable, el responsable es el Otro y el responsable de la propia satisfacción también es el Otro. De esta manera no es nada sencillo abandonar esos modos de satisfacción infantil, pueden durar mucho tiempo y hay una pérdida de modos de satisfacción conocidos, que se dirige a un desconocimiento. El adolescente pierde un tener por una incertidumbre; se abre un abismo del sin sentido en donde se alojan la angustia, la culpa, y la depresión. El adolescente tendrá que crear sus respuestas a lo real del sexo y una de ellas es el mantener sexo de manera indiscriminada.

Se examinó desde el psicoanálisis que el pasaje al acto y el acting out son varias de las alternativas que emplean los adolescentes para calmar su desasosiego. Hay adolescentes que buscan realizar actividades que les procuren intenso placer y de esa manera aplacar la tensión. Otros adolescentes manifiestan actitudes impulsivas con agresión sobre el propio cuerpo o sobre el cuerpo del otro; producen conductas de riesgo que les hacen sentir que pueden vencer a la muerte, que regulan la angustia que ocurre ante las pérdidas; actos que reemplazan a las palabras.

\section{Conclusiones}

Como conclusión se puede determinar que lo que sucede en la adolescencia es a nivel de la pulsión, el adolescente está del lado del empuje y del lado de la actividad pulsional que condiciona al sujeto separarse de los padres y cuestionar sus ideales, fuerza al sujeto a confrontarse con la castración en el Otro que se revela incompleto e inconsistente y surgen respuestas que comprometen la relación del sujeto con su cuerpo como es el mantener sexo indiscriminado.

\section{Referencias}

Aberastury, A. A. y. o. (1978). Adolescéncia.

Arvelo, L. (2003). Función paterna, pautas de crianza y desarrollo psicológico en adolescentes: implicaciones psicoeducativas. Acción pedagógica, 12(1), 2030 .

Fernández Mouján, O. (2002). Abordaje teórico y clínico del adolescente (n. ${ }^{\circ}$ Sirsi) i9789506021313). Editorial Paidós.

Recibido: 14 de junio de 2017

Aceptado: 30 de julio de 2017

Zambrano, Rosa María: Sicóloga Clínica de la Universidad Católica de Cuenca. Magíster en Psicoanálisis con Mención en Educación de la Universidad Católica Santiago de Guayaquil. Docente Universidad Católica de Cuenca Extensión San Pablo de La Troncal desde el año 2011 hasta la actualidad. Se desempeña como Subdirectora de las Carreras de Psicología Educativa y Orientación Vocacional; Educación Inicial y Parvularia. También ejerce en práctica privada en La Troncal desde el año 2010 hasta la fecha. Fue psicóloga clínica en la Clínica de Reposo Renacer en Guayaquil durante el período 2008- 2012; y trabajó en Atención al Programa de Protección a Víctimas y Testigos de la Fiscalía de La Troncal en el año 2013. Pertenece a la Comunidad Psicoterapéutica Luz y Vida La Troncal 2012. 
